\title{
The emergence and influence of food bloggers in India: The Instagram way of networking
}

\author{
Rashi Shah, Kritanshi Mishra \\ DOI: 10.29322/IJSRP.11.01.2021.p10974 \\ http://dx.doi.org/10.29322/IJSRP.11.01.2021.p10974
}

\begin{abstract}
As per the latest research there are 100 million Instagram users in India. Instagram plays a prominent role in influencing people in any aspect. This study focuses on examining the effect of Instagram food bloggers who promote healthy eating lifestyle on the users of Instagram. It examined various aspects of food blogging and its impact on the audience to move towards healthier lifestyle. The paper covers the tactics used by healthy food bloggers to influence people towards healthy eating lifestyle. To analyze the effect and its impact both the aspects were taken, of bloggers as well as followers followed by interview and survey respectively. The sample size is 200 respondents. Mean statistics is used to analyze the response. The results reveal that most of the audience are inclined towards following the healthy food bloggers on Instagram. The perceived credibility and perceived usefulness of food bloggers positively influences people's attitude towards healthy food which later influences their behavioral intention. The study found that food blogs have impact on encouraging people to eat healthy food, to raise awareness of the consumption of healthy food.
\end{abstract}

Index Terms- Food blogging, Instagram, Healthy food bloggers, Television Chefs, Veganism, Vegetarianism, Opinion Leaders, Social media, Influencers

\section{INTRODUCTION}

$\mathrm{F}$ ood has always been the factor that has drawn humans together for ages, as it is something everyone needs and is a central part of almost every culture. People have started to value healthy lifestyle more than ever because of the rapid increase in diseases like diabetes and cholesterol for which the most influential factor is high carb diet/food. Over the past years, the consummation of healthy food has become a trend and has been spreading all over in the society. This momentum started due to the increase awareness in eating healthy food habits in their daily life. According to study, 173 people out of 500 respondents purchased healthy food more than once per week.

Talking about trend, Social Media has been all over the internet, lately. Recent researches have shown that the social media is a popular tool for acquiring nutritional health information, especially among young adults. Earlier people were more influenced by information received through mass media but today, online social networks have power to influence consumers' purchase decision. Social media plays a huge role in influencing people as it impacts public opinion the most. Social media is among one of the highest forms of source of information for healthy food habits. Generally, Consumers consider social media advertising as an effective purchase decision medium.. The interest of healthy food in this digital era is now reflected in social media, where it has been discovered that there is an increase in number of uploads related to food on regular basis. This advancement of technology in social media made blogs become a crucial way to spread knowledge about food (Cox and Blake, 2010). That's how food blogging came into the picture and it has become one of the most influential profession. The primary reason behind food blogging being so influential and trusted is because it is user generated media which influences customer's behavioral intention.

One of the newest form of Social Media to influence modern day culture is Instagram. Instagram is a mobile photo- and videobased social media app, launched in 2010.Since the launch the app has rapidly increased its user base to over 600 million people. The largest profiles found on the platform are those of Polish celebrities, popular bloggers and brands. Many people use Instagram to support healthy behavior change. Instagram users follow healthy influencers on Instagram to support healthy food and healthy lifestyle and healthy lifestyle derives from consuming healthy food. Healthy food influencers are the one who promotes and supports healthy diet, who influence people to have a balanced meal every day and stay fit.

As, "Photos and videos have become the key social currencies online" healthy food influencers promotes healthy food through photos and videos. Some people post photos of food on Instagram to support their healthy goals, using it as an everyday tracking tool as they pursue healthy eating choices. Audience gets attracted towards attractive and creative photos and videos posted by the influencers. Influencers direct the audience to have a balanced meal and a perfect mal chart for the whole day through their Instagram posts.

Understanding people's mindset to follow the influencers (psychological factors) and what all other factors attract them to follow the influencers in daily life has the potential to inform system design to support healthy eating. Along with that what plays a vital role towards healthy eating system is how the influencer maintains his/her page. How creative he/she goes to attract the audience. They also provide with some astonishing recipes like Television chefs. As television chefs have become a household name and have gained a large number of loyal followers. They also play a vital role in influencing people towards healthy lifestyle. They have also become the driving force behind the creation and expansion of dedicated T.V. channels and syndicate reality T.V. shows, through which they promote to consume healthy and nutritious food along with its recipe.

Seeing the popularity of television chefs there arise a question, whether they can be considered as a celebrity or not, giving them 
the title of Celebrity chefs. To answer all the above research questions we have conducted a survey of some people who frequently uses Instagram and who are food freaks. We have also interviewed some influencers to know their tactics and creativity to attract the audience towards healthy food.

Food is considered as today's hottest social currency. To follow a healthy diet should be our aim in life, to remain fit and have a vigorous health. So this paper contains how to influence people to consume healthy food using trending method for today's era i.e. social media with a special reference of Instagram.

\section{REVIEW OF LITERATURE}

The social media has aroused a lot of interest among researcher and academicians. As use of social media is increasing at phenomenal rate and companies showing tendencies of allocating increasing budget to social media to communicate and

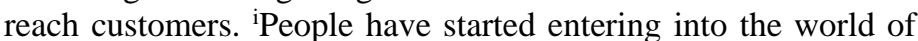
blogging and social media influencer which has managed to attract a large following. There are plenty of bloggers as well as influencers over the internet. However, their field of blogging may differ. The researchers have focused mainly on food bloggers/ food influencers. The paper fore mostly explains the concept of food blogging and further explains a brief history of food blogging. The researchers have interviewed few food bloggers who have decent fan base which resulted in finding out and analyzing the various aspects of food blogging and the tactics used by the bloggers to maintain their blog/feed. In addition, results indicate a slow shift of consumers towards healthier lifestyles such as vegan or vegetarian.

Since a major shift has been observed in the lifestyle of the consumers, a survey has also been done by the researchers to understand the consumers preferences which helped to examine the factors that influence consumers through online social network, particularly Instagram The customers ranked in order of importance relative content, trust, compatibility and field of interest as the factors that encouraged or discouraged them from following a particular food blogger/ food influencer.

Hence, the study has been assessed from both the aspect of blogging i.e., from an influencer point of view as well as their consumers.

\section{Research Objectives}

1) To study the emergence of food blogging community and the stages of becoming an influencer on Instagram.

2) The aim of this research paper is to find out what strategies do healthy food bloggers use to promote their Instagram page and attract more audience.

3) The difference of following and influencing level of healthy food bloggers and television chefs.

4) To study the psychological effect of healthy food bloggers on their followers.

\section{Research Methodology}

The present research starts with the problem definition, and in this case, it refers to a detailed understanding of food blogging, how it works and how it is influencing consumers to adopt eating habits.

This publication is licensed under Creative Commons Attribution CC BY.

http://dx.doi.org/10.29322/IJSRP.11.01.2021.p10974
From July to October 2020, the researchers carried out a quantitative evaluation of posts and interactions with users, in terms of feedbacks, comments and reactions to posts proposed by the some of the health influencers/ bloggers. We performed statistical analyses in order to detect the presence of any differences based on the type and form of the content of various famous food bloggers. Also conducted a survey for consumers and interviewed food influencers of Instagram.

The study is based on both primary as well as secondary research method.

\section{Research Gaps}

Review of literature suggests that a number of studies have been carried out to study the consumers' preferences as well as to understand it from the influencers' aspect.

Moreover, most of these studies have been mainly undertaken to understand the consumer's response towards healthy food influencers. As evident from the studies, there has been a rapid increase in consumers' preference towards health and wellness in the recent years due to significant increase in health consciousness and disposable income that resulted in following an influencer who promotes healthy lifestyle.

With a change in consumers' attitudes and perceptions regarding the health enhancing role of the healthy food influencers which consequently gives them motivation and that push to be healthier, there arises a need to study and analyze the demographic, psychological and the appeal factors affecting the following decision of the consumers. There is also a need for a better understanding of the motivational factors which have brought about a paradigm shift in the adopting healthy lifestyle and following food bloggers online leading to a new trend throughout the world, particularly in developing countries including India.

The Scopes of most of the existing studies are limited to food blogging in general. Moreover, there are no or very few studies on food bloggers that promote healthy lifestyle and consumers' preferences on food blogging in India.

As the Indian influencer industry is experiencing a significant growth, a comprehensive study on understanding their potential and consumer behavior for health and wellness food becomes important. Since there are plenty of food bloggers ranging from Nano-influencer to mega-influencers, it becomes quite difficult to cover all the aspects of its emergence. This study aims at filling the existing research gap in an emerging food influencer industry. This study begins with explaining the concept of food blogging with its history, current scenario in India, and focus on the aspects of food blogging and analyzing the consumers' preferences towards following a food influencer.

\section{HISTORY OF FOOD BLOGGING}

Over the years, food blogging has evolved rapidly. Food blogging was started way before it got the term "food blogging". This section of the research paper will further put the light on the timeline of food blogging.

\section{9}

In 1999, David Lebovitz, a professional chef, cookbook author (and now a blogger), whose cookbooks has already 
influenced a lot of consumers and made them go gaga over his temptingly delicious recipes, has developed a website of his own where he started posting updates on his influential baking and dessert recipes. He is a household name in the culinary world. There was a huge crowd in his website as it has become even more accessible to the consumer with the easy availability of internet. As the recipes are just not limited to the cookbooks and can be easily accessed by almost anyone, people have started loving this idea of website.

Also, a web-based blogging software called "blogger" was launched at that time.

\section{1}

In 2001, two food bloggers, Jason Perlow and Steven Shaw launched a food online discussion forum called eGullet. Since, blogger was already introduced by then, a blogger called named Bruce Cole, now a publisher, started a newsy influential blog called 'Sauté Wednesday' where he used to post food blogs.

\section{2}

The first cook-through blog was introduced by Julie Powell. This cook-through blog was like a web musing which is far more convenient to learn and gain knowledge about food through the web. Gradually, consumers have started considering such sites to be a part of the new web world in which people can learn from professional food writers/bloggers.

\section{3}

Introduction and launch of 'WordPress'. WordPress is a huge blogging app wherein people blog about anything they want to. However, this application got a lot of recognition among the eyes of bloggers and a huge wave of bloggers as well as readers started switching to 'WordPress'.

Following the trend, a lot of chefs and bloggers started shifting towards blogging as it was approached by masses and the follower base has also started increasing.

\section{5}

Since, the whole idea of delicious recipe blogs has already accelerated and was at its peak. Some bloggers started healthy blogs wherein they influence people to be fit and move towards gluten free diets because a lot of people are gluten-intolerant. Shauna James Ahern is one of the first bloggers to develop recipes for gluten-intolerant.

\section{6}

Twitter, an online social media platform, was launched. On twitter anyone from anywhere can create a social media account and follow people based on their respective interests. Since it has become very popular among people, bloggers have started sharing their blogs on twitter with photos. ${ }^{\text {ii These pictures attracted people }}$ and were appealing and tempting which managed to attract more followers.

\section{0}

A lot of social media platforms has come in the market but this application called 'Instagram' was launched by Kevin Systrom. Instagram is a photo and video-sharing social media application wherein a person can also write captions and use hashtags along with the photo. This application rose explosively among the youth and is still among one of the most used applications. Almost everyone from each and every corner of the world started using Instagram. With the video sharing option, food bloggers started sharing recipe videos which resulted in sudden rise in interest of the audience. With the help of video sharing option, food making and understanding the whole process has become exponentially easier and convenient for the consumers.

By this time a lot of blogging applications has entered in the web but social media platform aced the audience engagement which resulted in an explosive rise of the applications such as Instagram and Twitter. Social media platforms have become a popular tool for acquiring information, especially among young adults. Earlier people were more influenced by information received through mass media but today, online social networks have power to influence consumers and the person who influences a mass number of people are called as influencers. The largest profiles found on the platform are those of Polish celebrities, popular bloggers and brands. A lot of people even get influenced and motivated following Instagram influencers. This Influence could be of anything from fashion to choosing a particular lifestyle.

Looking in the present scenario, Instagram is hugely populated by bloggers, influencers and followers indulged in respective fields. Since the launch the app has rapidly increased its user base to over 600 million people. Using Instagram as a food photo database, people were easily able to identify food deserts and associate eating habits with locations. Food pictures are particularly prevalent, and the popularity of food images has drawn a lot of attention. Looking into the culinary side of it, various types of food influencer are on Instagram. From influencer's restaurants, junk food, homemade recipes to influencing people to shift toward healthier lifestyle and choices. Instagram has it all. However, there is a sudden shift of people following healthy lifestyle. People have become more aware of what they eat. They often seek fresh products, which are natural, organic and minimally processed. On a global level, youngsters are most willing to move towards cleaner lifestyle due to health attributes. As far as it goes, they are learning from mistakes of the previous generation and are ready to change their habits towards healthier nutrition. Following these influencers on social media people have started acquiring knowledge about food and especially about nutritional health information. Social media is among one of the highest forms of source of information for healthy food habits. Since the influence impacts public opinions so strongly, people have started following lifestyles of the influencers.

Even, some influencers give customized diet plans to the audience that's how people trust them because they've tried it and gives advice based on their experience which makes it even more trustworthy to the audience. People are increasingly seeking recipes through influencers. With the growing popularity of social media, health professionals must become aware of the quality of recipes information that is commonly available on them.

In the recent years, the concept of veganism has evolved from the vest and a lot of people are trying to adopt veganism. There has been rapid increase in the number of vegans across the world. 


\section{VEGETERANISM \& VEGANISM ON INSTAGRAM}

"Thou shalt not kill to eat"

Vegetarianism and veganism are two closely knitted terms. But veganism is so much more than just a diet, it's a lifestyle. A vegan lifestyle is a creed and a lifestyle that denounces the idea of animal cruelty. This concept of veganism evolved and is a direct import from the West. Vegetarianism and veganism have become quite popular in the West, as people in masses have started adopting plant-based and zero-waste lifestyle.

Recently, there is a major shift towards vegan lifestyle. Social media is a major driver of the vegan lifestyle, which partially accounts for the prevalence of veganism among millennials who gravitate toward social media. ${ }^{1}$ As of December 2019 , more than 95 million Instagram posts have been hash tagged with \#vegan or \#veganism, according to Instagram statistics (Instagram, 2019). ${ }^{\mathrm{iii}}$ In light of the prevalence of veganism among millennials and influx of \#vegan posts on Pro-veganism on Instagram. People are exposed to social media and as the world becomes smaller due to globalisation, veganism is increasingly being embraced.

However, the concept of veganism is still not completely accepted by the Indian consumers as India is predominantly a dairy-obsessed \&vegetarian country. Indians have traditionally been heavy consumers of dairy products. Dairy and cows are widely considered inherent to the cultural fabric of India. Other than this, Ayurveda has been practiced in India since time immemorial. Ayurveda is an alternative medicine system with historical roots in Indian subcontinent.it has various therapies that are mainly based on complex herbal compound, dairy etc. In fact, dairy plays a major role in Ayurvedic medication. It uses many dairy preparations medicinally which includes milk decoctions, ghee, gaumutra, etc. apart from that India is the number one milkproducing country in the world, and dairy products are a vital part of an Indian diet, in both rural and urban areas. Dairy products such as milk, butter, and cheese are ubiquitous among Indian consumers. Because both the factors are deeply inculcated in India and is practised by masses, complete abstain from animal products is not possible but India has the world's largest number of vegetarians.

To the world, India is often known as the land of Gandhi, spiritualism, and yoga - three sets of beliefs and practices closely associated with some form of vegetarianism. India has long been touted as the vegetarian capital of the world.Vegetarianism has been present in India since antiquity. Nevertheless, vegetarianism is both a powerful norm and an important performance. As a desired attribute of so-called upper caste groups, vegetarian norms are so desirable that they enforce periodic ritual abstinence.

Vegetarianism also evolved in modern India through conformity with Brahmanism and caste sensibilities, especially visible within the traditionally vegetarian upper castes like Jains and Buddhists. Jains in India are very influenced with vegetarianism, they are mostly lacto-vegetarians which means they consume plant-based food as well as dairy products.

Even though people in India are shifting towards veganism but largely rely on vegetarianism. That's why vegetarian food influencers are quite popular among the consumers. Food influencers such as Rujuta Diwekar (880K followers), Ranveer Allahbadia (1M followers) are very famous among the Indian audience. They promote healthy lifestyle along with vegetarian as well as vegan diets (to some extent).

We've conducted a survey on preferred diet which resulted that 120 out of 150 people, which mean $80 \%$ of the consumers are vegetarians and preferably follow vegetarian Influencers like Rujuta Diwekar etc.

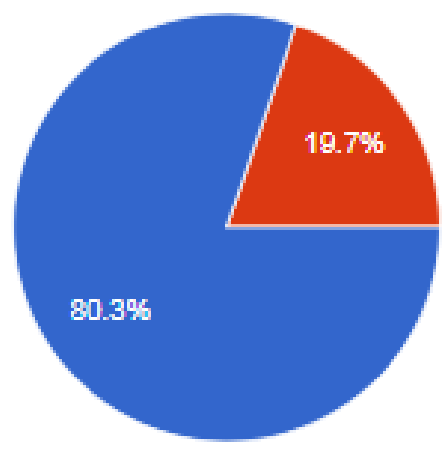

\section{STAGES OF BECOMING AN INFLUENCER}

Social media has become a popular tool for acquiring information through veterans, especially among young adults. Earlier, people were more influenced by information received through mass media but today, online social networks have power to influence consumers more than ever. Social media plays a huge role in influencing people as it impacts public opinion the most. The influence online is rapidly growing and evolving. Now that people have started following influencers and blogger so religiously, influencer marketing has become so mainstream, marketers are looking to tap into the next set of high-profile influencers to improve performance as it majorly influences consumers. Latest estimates predict influencer marketing spend will reach $\$ 5-10$ billion by 2020 . But becoming a successful influencer is not a cakewalk, especially when there is so much competition. In order to become a successful influencer, one has to start from scratch and build themselves through a lot of hard work, patience and consistency. Nothing comes easy. This growth phenomenon towards achieving success is often segregated into tiers according to one's growth, performance, reach as well as engagement. From a thousand followers to having more than millions, one has to go through each and every tier to be among the top influencers. the researchers have interviewed a few influencers and concluded that people often start blogging as a hobby and when they grow enough, they make it their profession. The tiers are divided into 5 subdivisions and these tiers are valid for each and every influencer (let it be fashion influencer or food influencer).

\footnotetext{
${ }^{1}$ https://munchies.vice.com/ en_uk/article/9a8gve/this-is-whymillennials-are-all-turning-vegan
}

This publication is licensed under Creative Commons Attribution CC BY

http://dx.doi.org/10.29322/IJSRP.11.01.2021.p10974 
The standard Instagram influencer tiers are as follows: Nano-influencers: $1,000-10,000$ followers.

Micro-influencers: $10,000-50,000$ followers.

Mid-tier influencers: 50,000 - 500,000 followers.

Macro-influencers: 500,000 - 1,000,000 followers.

Mega-influencers: 1,000,000+ followers.

\section{$>$ Nano-influencers}

Nano-influencers have small followings of roughly 1,000 to 10,000 users on Instagram, and are the latest tier to enter if a person wants to become an influencer. Since they have less followers, it makes them more approachable and they are often closely knitted with their audience which will attract strong engagement.

Food influencer generally start with posting content on the platform with the reviews. If they maintain their appealing feed and be consistent with their work, it will help them to gain more following.

Example of Nano-influencer is Anirudh Tripathi. He's a fitness enthusiast. Promotes fitness and healthy eating habits. Instagram handle: @anirudhtripathi_

\section{$>\quad$ Micro-influencers}

Micro-influencers are Instagram influencers with roughly 10,000 - 50,000 followers. Micro-influencers are considered as the most "buzzed about" influencer tiers. The excitement around micro-influencers is partly based on their ability to cultivate niche communities around specific interests of their followers. Microinfluencers are also commonly considered to have higher engagement rates than influencers with higher followings.

Example of Micro food influencer is Madhuri Ruia (15.8k followers). She is a nutrition specialist and influence people to follow healthy lifestyle with maintaining a stable balance with physical exercises.

Instagram handle: @madhuriruia

\section{$>$ Mid-tier influencers}

These influencers have a fan base ranging from 50,000 500,000 followers. Whereas smaller influencers generally manage their Instagram as a side hustle or as a hobby, mid-tier influencers can be considered as professionals since they secure more sizable sponsorships and many make a full-time living off of their Instagram presence. They have stronger reach than the micro- and Nano-influencers, but are still more accessible than macro- and mega-influencers that is why they are also called as middle-of-theroad influencers.

Overall, mid-tier influencers represent a happy balance between intimate fan communities and scalable audience reach.

Example of amid-tier influencer is Paola Marquez (143k followers). She's a lifestyle influencer as well as youtuber. She encourages women to navigate life with positivity and to build a sustainable habit for a healthy lifestyle.

Instagram handle: @paosfitworld

\section{$>$ Macro-influencers}

Macro-influencers are established Instagram stars with a sizable following of 500,000 - 1,000,000 followers. In almost all cases, their social media presence represents their entire source of income-either that, or they are actors, models, athletes, or musicians in their own right. They can be called as full-fledged influencers that make their living out of it.

Example of Macro food influencer is Rujuta Diwekar (880k followers). She's a nutritionist and promotes healthy vegetarian lifestyle.

Instagram handle: @rujuta.diwekar

\section{$>$ mega-influencers}

Mega-influencers are the ones who has achieved celebrity status on Instagram with a massive fan base of 1,000,000 or more followers. Their broad appeal and colossal follower count grant them a powerful position as cultural tastemakers. Megainfluencers shape popular culture, drive trends and hashtags, create sell-out demand for almost everything they promote.

Compared to influencers with niche followings, megainfluencers have the power to start a conversation with a much wider audience and drive larger cultural conversations.

Example of a mega-influencer is Ranveer Allahabadia (1M followers), popularly known as 'beerbiceps'. He's a content creator, youtuber and health influencer. He promotes pro vegan lifestyle.

Instagram handle: @ beerbiceps

\section{TACTICS USED BY HEALTHY FOOD BLOGGERS TO INFLUENCE THEIR FOLLOWERS}

Healthy food bloggers on Instagram plays a key role in influencing today's generation towards healthy eating habits. As photos and videos are today's hottest social currency, today's youth is more inclined towards internet and social media and the trend of shorter and visually appealing messages that are typified by photos and videos is gaining popularity and is becoming more persuasive and effective by today's audience. Instagram has revolunalized the physical approach of influencing people towards healthy diet to digitalized approach. Healthy food bloggers creates the content to influence people towards healthy eating lifestyle through digitalization. So Instagram allows its users to follow them on a basis of daily routine and users gain the knowledge and important tips from them towards eating healthy food and consuming vegetarian food. Such healthy food bloggers are more influencing in today's era where digitalization and use of social media applications like Instagram prevails.

So, to keep influencing more and more people towards healthy diet they are regularly active on Instagram and keep providing information, benefits and new tips on healthy diet. They regularly work to keep their feed creative especially by visually appealing images of healthy food. They brings out the positive aspect of consuming healthy food, and presents them to the audience in a more appealing way. Uniqueness and originality is the concept which is expected by the audience in each and every influencer and so to prevail this concept, they work on their selfpresentation on Instagram. Self-presentation plays an important role in building the image of healthy food bloggers. It is a way through which such individuals present themselves in front of the audience and manage their impression towards the audience. Instagram allows them to build their personal image (also promote their lifestyle) through the sharing of photos and videos. And this is the reason through which Instagram accounts of healthy food bloggers are gaining popularity in today's generation. Due to the 
tactics they use in gaining popularity and influencing people, they can also be termed as 'opinion leaders'. Healthy food bloggers who have reached to a high level of following on Instagram can be titled as opinion leaders. People follow them on a daily basis on a serious level as they have become highly influential to them. So their opinion matters a lot to the audience. Opinion leaders are seen to have public recognition and they are considered as an expert in influencing people in adopting healthy lifestyle. The information provided by him/her is considered interesting and their persuasiveness affects the audience towards positive approach of healthy diet.

A barrier to healthy food consumption is the tendency people have inferred that unhealthy food is tastier then healthy food. In an experiment, it was demonstrated that unhealthy food was believed to taste better, procure more pleasure while being consumed and was preferred by consumers with a more hedonic goal. It was referred as Unhealthy = Tasty intuition (UTI). To overcome this barrier and to change this concept from the people's eating habits, healthy food bloggers brings out some recipes with the combination of healthy and tasty. They promote the idea that 'food $=$ nutrition $=$ health' through their recipes. They bring out their recipes on Instagram through appealing images and videos of those dishes. They teach the audience how to use healthy and interesting ingredients in a tasty manner and make the dish astonishing. This is one of the important factor and tactic through which audience follow the influencers. They promote the consumption of healthy food through their creative and interesting messages on Instagram. They educate the audience on how unhealthy food affects their health and explains the positive effect of adopting a healthy lifestyle and eating habits on their life.

People don't have time nowadays to read and explore their knowledge through longer passages and messages. Today is the era where shorter messages along with photographs or graphical representations prevails. And so to influence people of today's era the healthy food bloggers uses various tactics and keep their Instagram feed creative and interesting. They try to implement more and more trending and prevailing material internet to their Instagram feed so that the audience doesn't get bored or dislike or unfollow their page. They work a lot to get positive feedback from the audience and try to avoid the negative comments from them. Healthy food bloggers on Instagram maintains a page on Instagram through which they influence people but some of them also writes blogs on the same to provide more information and educate in a more qualitative way. The food blogging aspect of the bloggers can be a professional work or a hobby. It depends from person to person. To gain some more insight into this topic, we have interviewed such a healthy food blogger. She is a professional nutritionist, giving advice to people to consume nutritional diet professionally. She also influences people for the same on Instagram. She also writes blogs providing nutritional information. While interviewing her, we asked her how influencing she thinks she has become. She answered that she receives positive feedback from the audience and so her following is also increasing due to which she thinks she is on the right track and feels positive and motivated to influence more people. Most important aspect of her blogging on Instagram is the larger reach as maximum number of people uses Instagram nowadays and also to increase public health awareness. Also, her surroundings, the atmosphere, the audience themselves motivates her to keep the feed creative which is a very positive point in this aspect. Also being the blogger she has to maintain the PR i.e. public relations with other bloggers, aspirants and audience too. With the help of this interview we can know how a healthy food blogger works, what is his/her intention and how do they promote $\&$ motivates people towards a healthier lifestyle. Also the blogger specified that most of her followers are youth and there are more number of female followers than male followers, which shows us that youth is more involved in staying healthy and fit as they are fond of social media app like Instagram.

\section{PSYCHOLOGY OF AUDIENCE IN FOLLOWING HEALTHY FOOD BLOGGERS ON INSTAGRAM ALONG WITH TELEVISION CHEFS}

\section{0 million users of Instagram in India.}

The above statement proves that today is the era of internet and social media. Social media is a platform where people quickly create and share content. Instagram is a social media application. It is an application specially used to share content through photos and videos. Photos and videos plays a very important role in today's era. People are very fascinated by the trend of sharing content through photos and video and that's how the healthy food bloggers influence people. People nowadays have become more of a fitness freak and trying to maintain a healthy diet. So to gain knowledge, information and tips of maintaining healthy eating habits people follow healthy food bloggers on Instagram. People follow such healthy food bloggers on Instagram because of shorter but important and useful messages which the bloggers upload through photographs. Due to the fascinating trend of photos and videos it is very easy to influence today's generation.

People follow healthy food bloggers on Instagram for many reasons. People of different age and gender follow such bloggers on Instagram. There are many factors which affect them to follow the bloggers. There are many aspects as well of following them. Some healthy food bloggers are very influential where as some are not. Due to the era of Instagram food bloggers have also gained fame among its followers. Healthy food bloggers on Instagram influences people towards consuming healthy diet and so do the television chefs does. Television chefs also influences people towards consuming healthy diet. They influence people through television as well as through Instagram. They also use Instagram to influence their followers towards healthy eating habits. They provide with various delicious and healthy recipes on Instagram as well as on television through various food channels.

The followers of both; healthy food bloggers and television chefs have different aspects and thinking and liking towards them. They follow them for different purposes and aspects. They may have different perception towards them as bloggers and chefs both of them have different level of fame and aspects in their professional life of influencing. So to answer the above research questions i.e.

- Difference of following healthy food bloggers and television chefs in terms of gender and age;

- Difference of following and influencing level between healthy food bloggers and television chefs; 
- The reason or need to follow the healthy food bloggers and television chefs' food content;

- Influencing level of healthy food bloggers towards a healthier lifestyle on a specified scale on their followers

We have conducted a survey of 150 people who frequently uses Instagram and actively follows healthy food bloggers on Instagram and television chefs. The methods of data analysis are descriptive analysis and quantitative analysis. Descriptive analysis is performed in order to know the psychological aspects of followers in following the bloggers and chefs. Quantitative analysis is performed in order to know the age, gender and the number of people following bloggers and chefs in daily life as an influencer and their frequency of following them.

\section{RESPONDENT'S PROFILE}

An exploratory research is used to provide insights into the psychological influence of food bloggers on consumers'. As a sampling technique, we used the convenience sampling technique which implies non-probability sampling. In order to obtain the answers for the research questions descriptive analysis and quantitative analysis were used as the data analysis method. From the quantitative analysis, it could describe respondent's profile, their gender, age, the frequency of following the bloggers and chefs. From the descriptive analysis it could describe psychological aspects of followers in following the bloggers and chefs. Mean statistics were used to analyze the response. These statistics can be obtained using frequencies, descriptive or explore command in SPSS. The analysis also includes graphical representation. In this case, the information was collected directly from respondents via the internet, from July to October, 2013, and the data analysis is quantitative.

The following tables records the characteristics of the respondents who answered the survey thorough online source. The sample size is of 150 respondents who are food freaks and want to maintain healthy diet.

\section{DEMOGRPHIC ASPECT}

The demographic question mainly includes the aspect of gender. It is to know the basic information of Indian population i.e. which gender is more inclined towards following healthy food bloggers and television chefs. It is to know the gender gap between following healthy food bloggers and television chefs.

\section{People following healthy food bloggers and television chefs on the basis of gender}

\begin{tabular}{l|r|r|r|r} 
& Frequency & Percent & Valid Percent & \multicolumn{2}{c}{$\begin{array}{c}\text { Cumulative } \\
\text { Percent }\end{array}$} \\
\hline $\begin{array}{l}\text { No } \\
\text { respon } \\
\text { se }\end{array}$ & 2 & 1.3 & 1.3 & 1.3 \\
\hline Female & 109 & 72.2 & 72.2 & 73.5 \\
\hline Male & 39 & 25.8 & 25.8 & 99.3 \\
\hline Total & 151 & 100.0 & 100.0 & \\
\hline
\end{tabular}

From the above table we can analyze that greater number of females follow healthy food bloggers and television chefs in India compared to male. There is a huge difference of following between the genders. The difference is almost of 50\%. Almost three times female than male are following healthy food influencers. There are many reasons for such a big difference. We also got to know the reasons from the survey questioner itself. From both the research i.e. primary as well as secondary we can analyze that India is a female oriented state in the aspect of food. Females in India are more inclined towards making edible food and getting information about the same. Also they are more interested in maintaining their diet in a proper manner. They are food freaks who are interested in easting tasty food in a healthy manner. So for the following reasons they do follow healthy food bloggers and television chefs on Instagram. But there are some percentage of male also which shows that India is not totally a female oriented country in the aspect of food and healthy diet. Some men are also interested in maintaining their diet and staying fit and healthy and so for the same purpose they follow healthy food bloggers and television chefs on Instagram. 
1. THE DIFERENCE IN FOLLOWING AND INFLUENCING LEVEL BETWEEN THE HEALTHY FOOD BLOGGERS AND TELEVISION CHEFS:

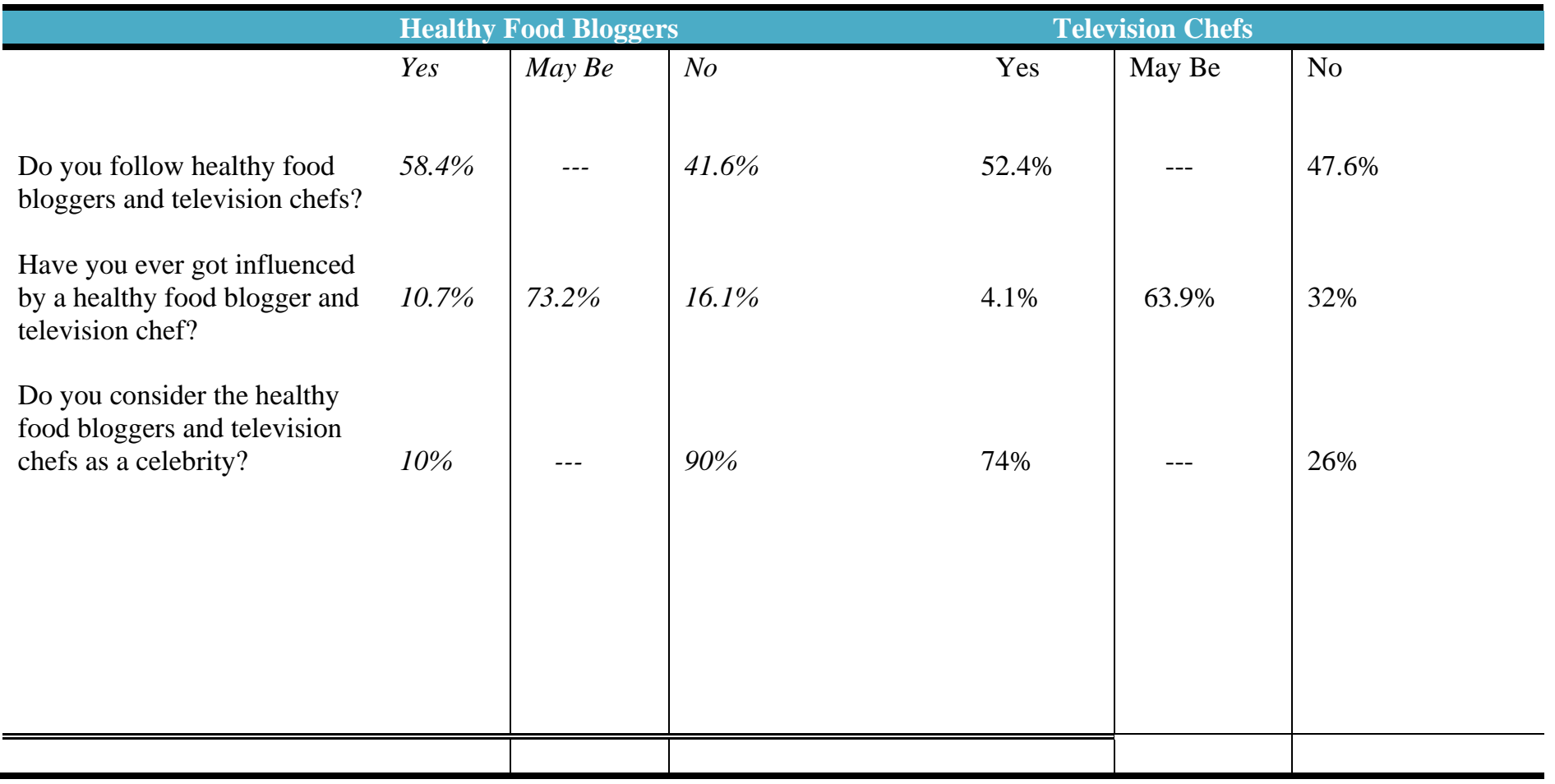

The above table shows the percentage difference between healthy food bloggers and television chefs in the aspect of following, influencing and their celebrity status on Instagram. Interpreting each we get the following analysis:

$>$ The first question represents weather the Instagram users follow healthy food bloggers and television chefs or not? In both the influencing field maximum number of people follow them. The difference in terms of percentage can be seen as there is a difference of $16.8 \%$ between the followers and non-followers in the following aspect of healthy food bloggers. While there is a difference of only $4.8 \%$ in the followers and non-followers of the television chefs. This shows that people of India are more interested in following healthy food bloggers and television chefs for gaining information and tips on healthy eating habits. The table also shows the difference between the percentage of following of healthy food bloggers and television chefs. It can be interpreted that more number of people follow healthy food bloggers than television chefs. This shows that the people are more inclined towards the information and tips given by bloggers. The influencing power of bloggers is more as compared to the chefs.

$>$ The second question represents if the followers have been influenced by the healthy food bloggers and television chefs or not? In both the influencing aspect it can be analyzed that it is neutral. The maximum number of followers feel that they may be influenced sometimes by them but not regularly. It represents the influencing power of both the influencers towards healthy food. It can be analyzed that most of the India's population is trying to follow the healthy eating habits through the tips and advice given by the influencers. But still they are not totally into it or else we can say that they are on the verge of adapting their lifestyle totally towards healthy eating habits.

The third question is related to the celebrity status of both the influencer. It is asked to the followers' weather they consider healthy food bloggers and television chefs as a celebrity? It can be clearly seen from the percentage in the table that maximum number of followers consider television chefs as celebrity but they does not consider healthy food bloggers as celebrity. In the research, we found out that it is because they consider healthy food bloggers on Instagram as a social media personality rather than a celebrity. So they give the status of celebrity to the television chefs and hence they are termed as 'Celebrity Chef'. 


\section{THE REASON AND NEED TO FOLLOW THE HEALTHY FOOD BLOGGERS AND TELEVISION CHEFS FOOD} CONTENT ON INSTAGRAM:

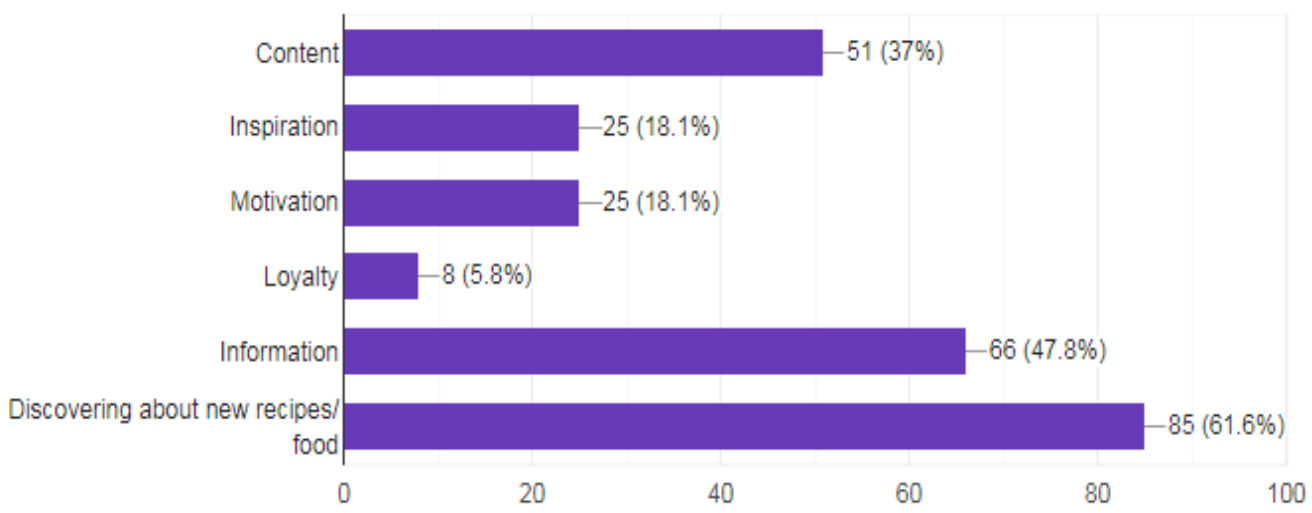

The above graph show the reasons due to which followers follow the content uploaded by the healthy food bloggers and television chefs on Instagram. It can be analyzed that most of the followers follow because them for discovering new recipes. They keep uploading new recipes which includes tasty as well as healthy dishes. Also the second maximum response is towards the information provided by the bloggers and chefs. According to our research they rely on the information provided by the influencers and follow them. Third most response receiving option id the content. Content is one of the most important aspect of the food bloggers and that is the reason due to which their Instagram account exist. Motivation and inspiration got the equal percentage of vote which means people do follow healthy food bloggers for the motivation and inspiration due to which later they also start adapting healthy eating habits. Loyalty factor also plays an important role in increasing the following. Loyalty builds by time and once you are highly influenced by a blogger loyalty will automatically build up, but stated above the followers are not totally influenced towards them this can be concluded as per the research that a little more time is required to build up that influential and loyalty level in the followers.
We also asked some question during the survey to the followers regarding their aspects of following the influencers. The questions were:

- You follow food influencers to learn about healthier lifestyle?

- On seeing a food influencer eating a meal, you get motivated to eat the same!

- You trust the recommendation by food influencers if they recommend anything to eat or purchase from any brand.

- Food influencers on Instagram are a reliable source of information about healthy food/diet?

They were required to answer the above questions through a rating scale from 1 to 5 . The scale from 1 to 5 included rating options as: 1- strongly agree, 2- agree, 3- neutral, 4- disagree, 5strongly disagree.

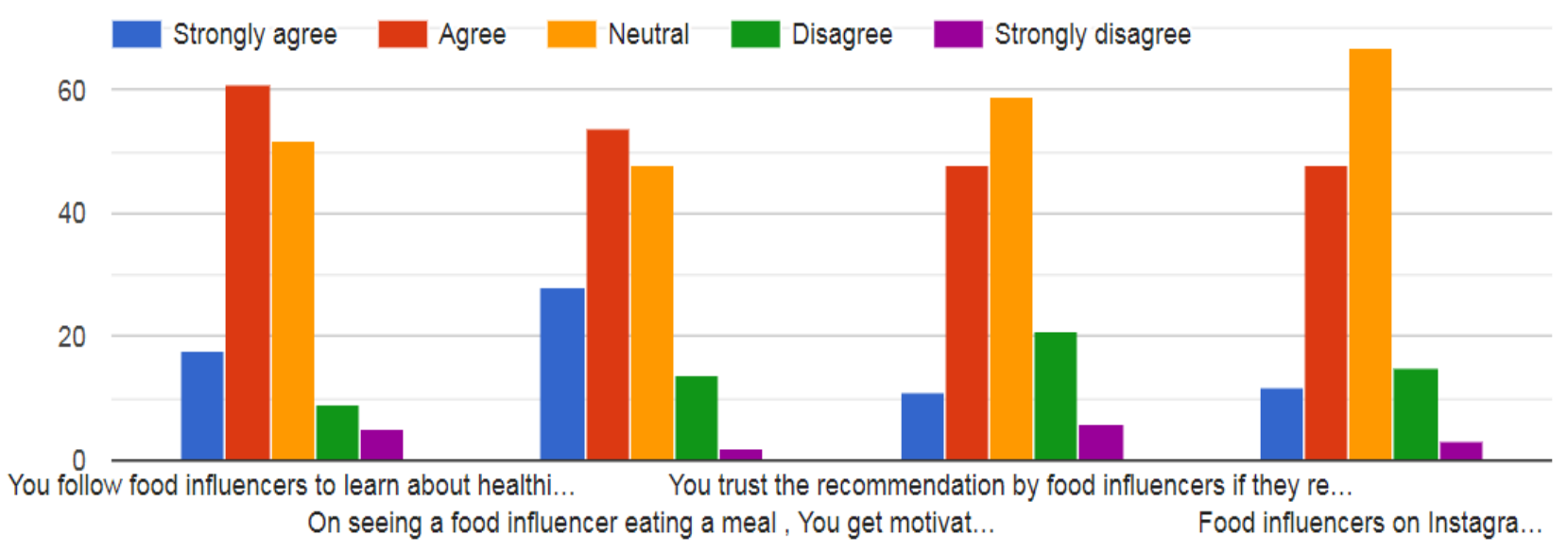


The above bar graph shows the percentage of responses of the followers for the above 4 questions.

\section{INFLUENCING LEVEL OF HEALTHY FOOD BLOGGERS TOWARDS A HEALTHIER LIFESTYLE:}

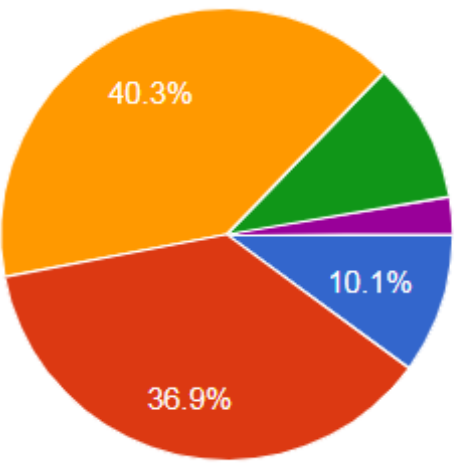

During the survey we asked the followers weather the influencers are really influencing them towards a healthier lifestyle? They were asked to rate their influencing level towards healthier lifestyle on a rating scale of 1 to 5 . Where, 1 -strongly agree, 2- agree, 3- neutral, 4- disagree, 5- strongly disagree. The response was almost neutral. Maximum number of followers responded that it is neutral that means they are not totally influenced towards healthier lifestyle. They need more appropriate information and motivation to divert themselves completely towards the healthier lifestyle. It is not a bad aspect but as stated above it will still take some time from both the end i.e. from the side of the influencer as well as the follower to completely adapt the healthy eating habit and lifestyle. But it can also be analyzed that after neutral the maximum number of percentage belongs to the option of 'agree' which means that many followers are really getting shifted towards the healthier lifestyle on the guidance of the healthy food bloggers which is a very positive aspect of the research.

4. During the survey we also asked the followers 'according to you, why are food influencers/chefs so popular? What factors does influence you to follow them?' and their responses were amazing. It depicted a lot about their perception and need towards the healthy food bloggers. Some of the responses are presented below:

\author{
Strongly agree \\ Agree \\ Neutral \\ Disagree \\ Strongly Disagree
}

Food influencers potray the food item very deliciously and this is the main reason they are popular. I mainly follow food infuencers on youtube and they kind of potray the food item in a very tempting way.

New recepies and health tips

Food Influencers leads people to live a healthier lifestyle and have healthy eating habits, hence food influencers are an inspiration to many as they are making people lives healthier by making change in their routine meals and scheduling a healthy diet meal with a spark of sapidity. In my perception, these are the factors that influence people to look up to them.

They explore the new combos or say unique fussions

One might find the ideas about healthy food habits and a way to live a disease- free life by following food bloggers/influencers.

And in these hard times, proper nutritive and healthy food is a must for everyone to lead a healthy life. This could be one of the reasons why food bloggers/influencers are more popular nowadays.

Everyone is a foddie nowadays

For healthy food they really suggest good stuffs like proteins rich food, vitamin, carbohydrate and they also suggest what should we eat to make our life better to overcome future diseases soo that's really nice. 
recipes. I do get influence by them because the way they show their food item or i would be clear the way they present there content on social media is so attractive.

Their authenticity...

Their new techniques and style of cooking..

They guide us in preparation of dishes as well as developing new recipes.

The level of content they produce and rhe hard work that they put in to create that content. Also, the different types of cuisines and the level of information they possess on it

Creativity of course counts a lot in what they do.

From my personal reasons i only follow them to get to know about new recipes!! And new places to discover

Because they focus on goodness from the inside. I pretty much like the inside out approach and also the fact that good and healthy food makes you feel better and peaceful in the long run.

They are because of their content. I follow them to gain knowledge about the food culture around the world. And to learn about new recipes.

Because they follow their passion...and they work hard to provide you best knowledge..

\section{CONCLUSION}

From the above survey we can analyze that people are interested in following healthy food bloggers on Instagram and they are really appreciating the bloggers for their work and influencing level. They are following them for many reasons as listed above and feels that their content of recipes is worth following and this is one of the main reason of following healthy food bloggers on Instagram as they provide them with delicious recipes for healthy eating habits.

People are getting influenced by the healthy food bloggers on a personal level itself but still it can be seen that they are not totally inclined towards their influencing power. It will still take some time from both the ends to make it totally based on the influencing level of the healthy food bloggers on a daily life basis and without opting for any other source for healthy diet information as the response from the survey was neutral when asked about influencing level of the healthy food bloggers.

\section{REFERENCES}

[1] Theodosia C. Nathalia, Carla Kansius, Eunice Felicia, Ida Ayu Amanda Kalpikasari (2016), The Influence of Food Blogger to the Intention of Consuming Healthy Food, https://www.atlantispress.com/proceedings/ictgtd-16/25868933

[2] Networks in allowing firms to leverage valuable (2015), https://www.coursehero.com/file/p2ahcnub/networks-in-allowing-firms-toleverage-valuable-information-andor-resources/

[3] George Waters(2019), Joy of eating has been forgotten| North Bay Nugget, https://www.nugget.ca/opinion/columnists/joy-of-eating-has-been-forgotten

[4] Joe Phua, S. Venus Jin, Jihoon (Jay) Kim (2020), Pro-veganism on Instagram: Effects of user-generated content (UGC) types and content generator types in Instagram-based health marketing communication about veganism, https://www.emerald.com/insight/content/doi/10.1108/OIR-062019-0213/full/html?skipTracking=true

[5] Aseem Hasuain \& Abhilasha Shrivastava (2018), What makes Indian vegetarians different from Westerners who have given up meat?, https://scroll.in/article/872951/what-differentiates-vegetarianism-practicedby-indians-from-that-followed-by-the-west

[6] Joslyn Chittipally (2019), Veganism in India, how the dairy-loving country is embracing a plant-based diet, https://www.lifegate.com/veganism-in-india

[7] Influencer tiers for influencer tier marketing(2018), https://mediakix.com/influencer-marketing-resources/influencer-tiers/

[8] Ali Haider Sandhu, A 5 point likert scale was used where 1 strongly agree, https://www.coursehero.com/file/p5oof5s2/A-5-point-likert-scale-was-usedwhere-1-Strongly-Agree-2-Agree-3-Neutral-4/

[9] Maike van't Laar, 4245814, BA Eindwerkstuk: Media en culture, NMDC: Stefan Werning, Period 4, 2016/2017, July 20, 2017. The Self-Presentation of Vegans on Instagram http://dspace.library.uu.nl/handle/1874/353539

[10] Akhil Mohan Pillai MARKETING METHODOLOGY USED IN THE FOOD INDUSTRY \& CONSUMER BEHAVIOR IN THE FOOD INDUSTRY July 2014 https://www.researchgate.net/publication/271530447_MARKETING_MET HODOLOGY_USED_IN_THE_FOOD_INDUSTRY_CONSUMER_BEH AVIOR_IN_THE_FOOD_INDUSTRY

[11] My Tran, An Instagram is worth a thousand words. The utilization of Instagram as a key social media marketing strategy. Case: Valona Design. https://core.ac.uk/download/pdf/80987091.pdf

[12] Ioanas Elisabeth Ioanas Elisabeth, Social Media and its Impact on Consumers Behaviour, January 2014 https://www.researchgate.net/publication/313421625_Social_Media_and_it s_Impact_on_Consumers_Behavior

[13] Anastasios Zopiatis (Department of Hotel and Tourism Management, Cyprus University of Technology, Limassol, Cyprus), Yioula Melanthiou (Department of Marketing, University of Nicosia, Nicosia, Cyprus), International Journal of Contemporary Hospitality Management. The celebrity chef phenomenon: a (reflective) commentary https://www.emerald.com/insight/content/doi/10.1108/IJCHM-12-20170822/full/html

[14] CharlesSpencea Katsunori Okajimab Adrian David Cheok OliviaPetitc CharlesMichela. Eating with our eyes: From visual hunger to digital satiation https://www.sciencedirect.com/science/article/pii/S0278262615300178

[15] Kate Ginsberg, Strategic Communications, Elon University Instabranding: Shaping the personalities of the top food brands on Instagram. https://www.semanticscholar.org/paper/Instabranding\%3A-Shaping-thePersonalities-of-the-TopGinsberg/612173b431cccdeee12f4d94bc6f6e4c8355d534

[16] Albane Duchamp, European Master in Business Studies, Student Number (Kassel): 35195427 How can social media influence users on the issue of healthy lifestyle? http://www.uni-kassel.de/fb07/fileadmin/datas/fb07/5Institute/IBWL/Wagner/EMBS/duchamp_albane_expose.pdf

[17] Chia-Fang Chung,1 Elena Agapie,1 Jessica Schroeder,2 Sonali Mishra,3 James Fogarty, 2 and Sean A. Munson1 "When Personal Tracking Becomes Social: Examining the Use of Instagram for Healthy Eating" https://www.ncbi.nlm.nih.gov/pmc/articles/PMC5432132/

[18] Jaroslaw Nadobnik, The use of selected social media: Instagram to promote physical activity and a pro health lifestyle. https://www.researchgate.net/publication/338892840_The_Use_of_Selected _Social_Media_Instagram_to_Promote_Physical_Activity_and_a_ProHealth_Lifestyle 
[19] Luis V.Casalóa Carlos Flaviánb SergioI báñez-Sánchez, Influencers on Instagram: Antecedents and consequences of opinion leadership. https://www.sciencedirect.com/science/article/pii/S0148296318303187

[20] Theodosia C. Nathalia, Carla Kansius, Eunice Felicia, Ida Ayu Amanda Kalpikasari Hospitality Management, Sekolah Tinggi Pariwisata Pelita Harapan, Tangerang, Indonesia, "The Influence of Food Blogger to the Intention of Consuming Healthy Food" https://www.academia.edu/36391034/The_Influence_of_Food_Blogger_To _The_Intention_Of_Consuming_Healthy_Food

\section{AUTHORS}

First Author - Rashi Shah

Second Author - Kritanshi Mishra 